\title{
Testing the Aspect First Hypothesis: A preliminary investigation into the comprehension of tense in child Greek
}

\author{
Sophia Delidaki \& Spyridoula Varlokosta* \\ University of Reading \\ 1lr02sd@reading.ac.uk \& s.varlokosta@reading.ac.uk
}

\begin{abstract}
Crosslinguistic research on the production of tense morphology in child language has shown that young children use past or perfective forms mainly with telic predicates and present or imperfective forms mainly with atelic predicates. However, this pattern, which has come to be known as the Aspect First Hypothesis, has been challenged in a number of comprehension studies. These studies suggest that children do not rely on aspectual information for their interpretation of tense morphology. The present paper tests the validity of the Aspect First Hypothesis in child Greek by investigating Greek-speaking children's early comprehension of present, past and future tense morphology as well as the role that lexical aspect plays in the early use of tense morphology. It is suggested that although Greek-speaking children have not yet fully mapped the tense concepts to the correct tense morphology, tense acquisition does not seem to be significantly affected by the aspectual characteristics (i.e. the telicity) of the verb.
\end{abstract}

\section{$1 \quad$ Introduction}

Research on the acquisition of tense in the past thirty years has shown that young children (under the age of 2;6) use their tense and aspect forms in certain restricted patterns: Past or perfective forms are used mainly with telic predicates while present or imperfective forms are used primarily with atelic predicates. This pattern has come to be known as the Aspect First Hypothesis and has mainly been based on production data that have been observed in a number of languages, including English (Bloom, Lifter \& Hafitz 1980; Shirai \& Andersen 1995), French (Bronckart \& Sinclair 1973), Greek (Stephany 1981), Hebrew (Berman 1983), Italian (Antinucci \& Miller 1976), and Turkish (Aksu-Koç1988), among others.

However, research on the comprehension of tense morphology has casted some doubt on the Aspect First Hypothesis, in particular on the role of lexical aspect in the interpretation of tense morphology. In a series of comprehension studies, Richard Weist and his colleagues (Weist 1991; Weist, Lyytinen, Wysocka \& Atanassova 1997; Weist, Atanassova, Wysocka \& Pawlak 1984) have shown that by the age of $2 ; 6$ children understand the tense semantics associated with tense morphology. This finding suggests that children's interpretation of tense morphology is not driven by aspectual information. More recently, Wagner (1999) has shown that English-speaking children as young as 2;9 understand present, past and future tense in an adult-like way and that their comprehension of tense morphology does not seem to depend on lexical aspect information.

We would like to thank Colin Grayer from the Department of Applied Statistics for his statistical advise. The second author would like to greatfully acknowledge the University of Reading Travel Grant SubCommittee for a grant that supported presentation of this paper at the Workshop on the Acquisition of Aspect, which was hosted at ZAS, Berlin in 9-10 May 2003. 
In this paper we investigate the validity of the Aspect First Hypothesis in child Greek by testing Greek-speaking three-year old children's comprehension of tense. The basic goals of our study were: a) to test children's comprehension of tense morphology, in particular their comprehension of present, past and future tense; b) to explore the role that lexical aspect plays in children's early use of tense; c) to examine the role that linguistic cues, such as time adverbials, may have to the comprehension of tense morphology.

\section{Children's early production and comprehension of tense morphology}

Production studies on the acquisition of tense in the past thirty years have revealed the following pattern: Tense morphology in early child language expresses aspectual rather than deictic relations. More specifically, the claim maintained by a number of researchers is that in the initial stages of acquisition children (under the age of 2;6) use their tense and aspect forms in certain restricted patterns: Past or perfective forms are used mainly with telic predicates (that is, predicates that have an inherent end-point in their meaning, e.g. break) while present or imperfective forms are used primarily with atelic predicates (that is, predicates that lack such an inherent end-point, e.g. ride). This pattern, known as the Aspect First Hypothesis, has been observed in a number of languages, including English (Bloom, Lifter \& Hafitz 1980; Shirai \& Andersen 1995), French (Bronckart \& Sinclair 1973), Greek (Stephany 1981), Hebrew (Berman 1983), Italian (Antinucci \& Miller 1976), and Turkish (AksurKoç 1988), among others. Stephany (1981), in particular, suggests that there is evidence for the Aspect First Hypothesis in the acquisition of Greek. She observes that between the ages of 1;8 and 1;11 children learning Greek never use imperfective past forms; instead, children's past tense forms have always perfective morphology. Stephany (1981) further points out a correlation between the semantic class of the verbs used by children and the classes of expressions in which these verbs are most characteristically used: Past perfective expressions only occur with dynamic verbs, most of which describe situations with a clear end-point. Present tense expressions, on the other hand, occur almost exclusively with stative verbs. Thus, Stephany (1981: 4) concludes that the desription of situations in early child language is non-deictic.

However, the Aspect First Hypothesis has been challenged in a series of comprehension studies. Richard Weist and his colleagues (Weist 1991; Weist, Lyytinen, Wysocka \& Atanassova 1997; Weist, Atanassova, Wysocke \& Pawlak 1984) have used a sentencepicture-matching task to assess children's comprehension of tense morphology. In this task children were presented with two pictures, for example one depicting a future (yet to come) situation (e.g. a girl about to throw a snowball) and the other depicting a completed situation (e.g. someone getting hit by a snowball that a girl threw) and had to match these pictures to two sentences (e.g. The girl will throw a snowball and The girl threw a snowball). Children acquiring English were found to perform better than chance on this task by the age of 2;6. This evidence is taken to indicate that the initial tense system is not as defective as the Aspect First Hypothesis assumes and that children do not mis-assign aspectual information to tense morphology. ${ }^{1}$

The results reported by Weist and his colleagues have been criticised by Wagner (1999) on the basis of the fact that their tense comparisons always involved the future tense, that is children always had to choose between a future/present contrast or a future/past contrast.

Further evidence for this conclusion is drawn from Polish child language (Weist, Wysocka, WitkowskaStadnik, Buczowska \& Konieczna 1984; Weist, Wysocka \& Lyytinen 1991). 
Given that the future tense has modal properties too, the success that children had in this task could easily be attributed to their knowledge of a realis vs. irrealis distinction. A further shortcoming of Weist's research that Wagner (1999) points out is the lack of a telic vs. atelic distinction in the test predicates used. The fact that all the test sentences used were telic made it difficult to determine the extend to which the predicate's lexical aspect influenced the interpretation of tense morphology.

In an attempt to address these shortcomings, Wagner (1999) designed a new study which tested the comprehension of past, present and future tense in 46 English-speaking children aged $1 ; 11$ to $4 ; 4$. In her experiment, children were presented with an illustration of a road and were introduced to a toy kitty that was performing the same event in three distinct locations along the road (initial, middle/ongoing and final/untouched location). While the kitty was in the middle of performing the event for the second time (i.e. in the middle location), the experimenter asked the child three questions which corresponded to one of the three locations in which the kitty was performing the event: Where was the kitty V+ing? (past tense question corresponding to the initial location), Where is the kitty $V+i n g$ ? (present tense question corresponding to the middle location) and Where's the kitty gonna V? (future tense question corresponding to the final location). In order to test the role that lexical aspect plays in the interpretation of tense morphology, Wagner used three telic (fill in a puzzle, empty out a cup, draw a face) and three atelic predicates (rest, play with a friend, hop around). The results showed that children did have some problems with past tense, but overall they had a preference to match each tense to the correct location, without being influenced by the lexical aspect (i.e. the telicity) of the verb.

\section{$3 \quad$ Greek aspect and tense}

The present paper investigates the validity of the Aspect First Hypothesis in child Greek. Greek is a language that encodes not only lexical aspect (information about the completeness of an event, i.e. telic vs. atelic events) but grammatical aspect too (information about the presence or absence of initial and final points in the description of a situation). Thus, Greek makes an aspectual distinction between perfective and imperfective aspect marked on the verb stem. Perfective aspect views a situation in its entirety, whereas imperfective aspect views a situation from within (Comrie 1976). Grammatical aspect is independent of lexical aspect. Thus both telic and atelic predicates may appear with either perfective or imperfective aspect. Grammatical aspect is also marked distinctly from tense. Thus, the aspectual distinction perfective vs. imperfective shows up in the past and future tense. The present tense, however, makes no aspectual distinction; only the imperfective stem is used. The interplay of grammatical aspect and tense with telic and atelic verbs is shown in Table 1.

Table 1. Interplay of grammatical aspect and tense with telic and atelic verbs in Greek

\begin{tabular}{|l|l|l|}
\hline & Perfective & Imperfective \\
\hline Present & n.a. & $\begin{array}{l}\text { pez-o (I play) [ATELIC] } \\
\text { xtiz-o (I build) [TELIC] }\end{array}$ \\
\hline Past & $\begin{array}{l}\text { epeks-a (I played) [ATELIC] } \\
\text { extis-a (I built) [TELIC] }\end{array}$ & $\begin{array}{l}\text { epez-a (I was playing) [ATELIC] } \\
\text { extiz-a (I was building) [TELIC] }\end{array}$ \\
\hline Future & $\begin{array}{l}\text { tha peks-o (I will play) [ATELIC] } \\
\text { tha xtis-o (I will build) [TELIC] }\end{array}$ & $\begin{array}{l}\text { tha pez-o (I will be playing) [ATELIC] } \\
\text { tha xtiz-o (I will be building) [TELIC] }\end{array}$ \\
\hline
\end{tabular}




\section{Our study: Greek tense comprehension}

\subsection{Design and procedures}

Our experiment tested children's comprehension of three tenses in Greek, present, past and future, following the basic design of Wagner's (1999) experiment. Each child was presented with an illustration of a road drawn on a piece of paper and was introduced to a rabbit-doll that enjoyed performing various events on the road. The rabbit performed an event three times in three separate locations along the road, the initial, the middle/ongoing and the final/untouched location. ${ }^{2}$ While the rabbit was in the middle of performing the event for the second time (i.e. in the middle location), the experimenter asked the child about the event in either the past, the present or the future tense.

In order to check the interaction of lexical aspect with tense morphology, six events, three of which were telic and three atelic, were acted out with the rabbit and the relevant toys. The telic events were: xtizo ena spiti 'build a house', ä̈iazo mia kupa 'empty out a cup' and zoãrafizo ena prosopo 'draw a face'. The atelic events were: pezo me enan filo 'play with a friend', ksekurazome 'rest' and agaliazo ena alogo 'hug a horse'. In order to check the role of grammatical aspect, the questions were formed with both perfective and imperfective aspect for the past tense. Consequently, the six events were performed in two phases: in the first one the past question was formed with perfective past and in the second one it was formed with imperfective past. Therefore, a total of 12 test sentenses were administerd to the subjects (phases 1 and 2). In addition, the six events were performed a third time as well, using time adverbials in the questions (phase 3). As in Wagner's (1999) study, linguistic cues such as time adverbs were expected to help children significantly. The adverbs used were: prin 'before' for the past, tora 'now' for the present and meta 'next' for the future tense control questions.

The three phases are illustrated in Table 2 for the atelic verb ksekurazome 'rest':

Table 2. Test and control questions for the atelic verb ksekurazome 'rest'

\begin{tabular}{|l|l|}
\hline \multicolumn{2}{|c|}{ Phase 1 (test sentences - perfective past form) } \\
\hline Past & $\begin{array}{l}\text { Pu ksekurastike o laãos? } \\
\text { where rest-3sg/past/perf. the rabbit } \\
\text { 'Where did the rabbit rest?' }\end{array}$ \\
\hline Present & $\begin{array}{l}\text { Pu ksekurazete o laãos? } \\
\text { where rest-3sg the rabbit } \\
\text { 'Where is the rabbit resting?' }\end{array}$ \\
\hline Future & $\begin{array}{l}\text { Pu èa ksekurasti o laãos? } \\
\text { where will rest-3sg the rabbit } \\
\text { 'Where will the rabbit rest?' }\end{array}$ \\
\hline
\end{tabular}

2 As the rabbit proceeded from location to location, it left footprints on the road. This was done with the help of ink placed on the rabbit's feet. The footprints helped the children to understand the procedure and to keep visual contact with the rabbit's path. As a result, the road had to be changed for each event that was taking place, in order for a new path to be created. 
continuing table 2 .

\begin{tabular}{|l|l|}
\hline \multicolumn{2}{|c|}{ Phase 2 (test sentences - imperfective past form) } \\
\hline Past & $\begin{array}{l}\text { Pu ksekurazotan o laãos? } \\
\text { where rest-3sg/past/imperf. the rabbit } \\
\text { 'Where was the rabbit resting?' }\end{array}$ \\
\hline Present & $\begin{array}{l}\text { Pu ksekurazete o laãos? } \\
\text { where rest-3sg the rabbit } \\
\text { 'Where is the rabbit resting?' }\end{array}$ \\
\hline Future & $\begin{array}{l}\text { Pu èa ksekurasti o laãos? } \\
\text { where will rest-3sg the rabbit } \\
\text { 'Where will the rabbit rest?' }\end{array}$ \\
\hline
\end{tabular}

\begin{tabular}{|l|l|}
\hline \multicolumn{2}{|c|}{ Phase 3 (control sentences with time adverbials) } \\
\hline Past & $\begin{array}{l}\text { Pu ksekurastike o laãos prin? } \\
\text { where rest-3sg/past/perf. the rabbit before } \\
\text { 'Where did the rabbit rest before?' }\end{array}$ \\
\hline Present & $\begin{array}{l}\text { Pu ksekurazete o laãos tora? } \\
\text { where rest-3sg the rabbit now } \\
\text { 'Where is the rabbit resting now?' }\end{array}$ \\
\hline Future & $\begin{array}{l}\text { Pu èa ksekurasti o laãos meta? } \\
\text { where will rest-3sg the rabbit next } \\
\text { 'Where will the rabbit rest next?' }\end{array}$ \\
\hline
\end{tabular}

Within each phase, the past, present and future questions were uttered in a different order to avoid any sequencing effect. The right answer for the past question was the initial location, where the action had already been completed or just performed. For the present question, the child should point at the middle location, where the action was still taking place. Finally, the correct answer for the future question was the last (not yet touched by the rabbit) location. However, as also pointed out by Wagner (1999), at least within phase 2 (imperfective past) of our experiment, the middle (ongoing) location was in principle a potential correct answer for each of these questions. Since the test question is asked after the second event has begun, a past tense description is possible for the imperfective past form since this form does not entail completion of the event. Also, since the test question is asked before the second event has culminated, a future tense description of the event is possible since the event will continue for at least a few seconds into the future. Nonetheless, as it will become evident in section 4.3, the proportion of the initial and the untouched location for the past and future tense questions respectively was high enough to suggest that this task is not invalid.

\subsection{Subjects}

Eighteen Greek-speaking monolingual children from the Athens area, eight boys and ten girls, participated in the experiment. Their age was between $2 ; 7$ and 4;0 years old, with a general mean age of 3;2 years. In our analysis we divided the children in two smaller age groups: the younger group consists of nine children with mean age $2 ; 8(2 ; 7$ to $3 ; 1)$ and the older one of nine children whose mean age is $3 ; 6(3 ; 2$ to $4 ; 0)$. Since no pre-test was used as in Wagner's (1999) study, an additional five subjects were excluded from the final calculations: three children failed to complete the test, a fourth child was pointing always to the future location and a fifth child did not demonstrate willingness to point. 


\subsection{Results and discussion}

In our experiment, as in Wagner's (1999), children were given three possible answers to each question: the initial location -which is the correct one for the past tense question-, the middle/ ongoing location -which is the correct one for the present tense question- and the final/not yet touched location -which is the correct one for the future tense question. Consequently, children had a chance level performance of $33 \%$ to indicate one of the three locations on the road. Thus, we will need a percentage of above $50 \%$ in order to cons ider the answer provided as a significantly important one.

In Figure 1 we present the mean percentage of correct answers for test (phases 1 and 2) and control (phase 3) conditions for each type of question (past, present, future) and for each age group (old and young).

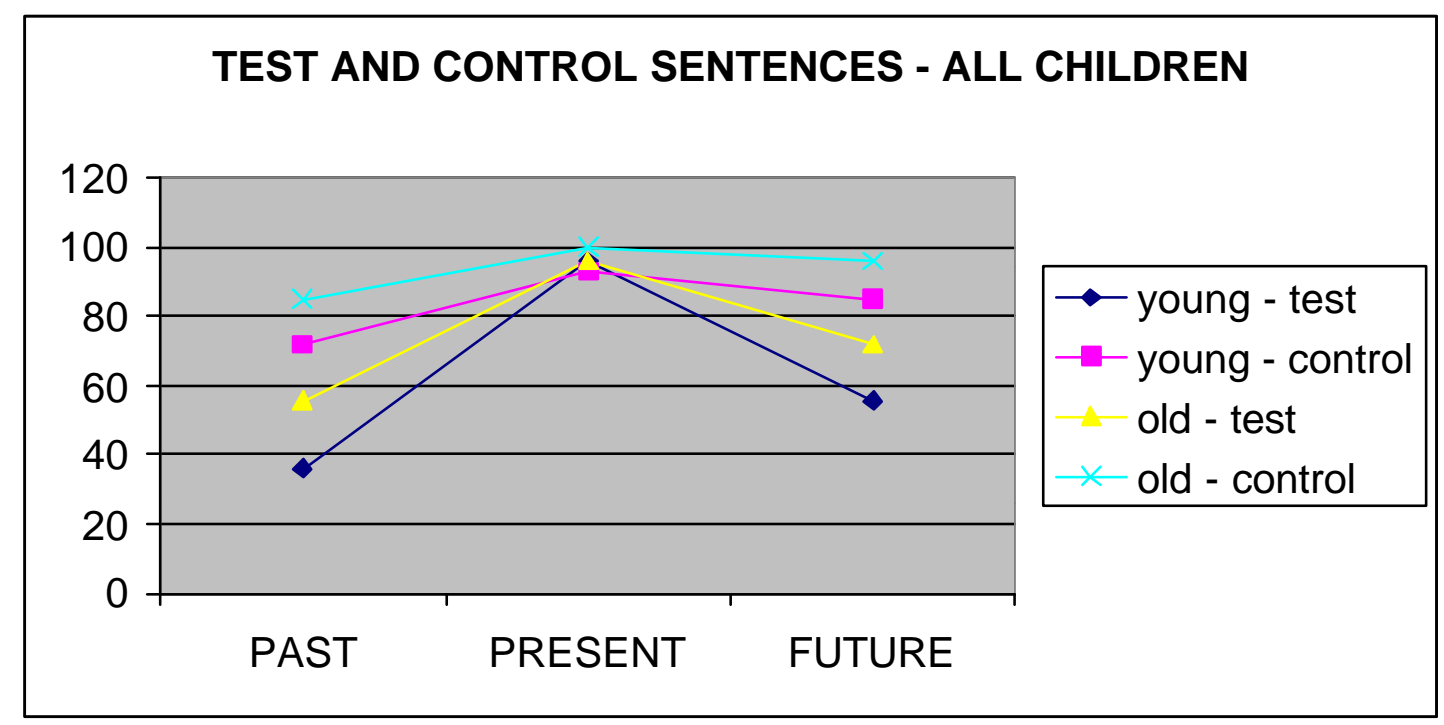

Figure 1. Mean percentage of correct responses for test and control sentences for each age group

There are two main observations regarding Figure 1. First, the presence of time adverbials in the control questions (for past and future questions) improved children's performance in each age group. A two proportions test was performed and the results indicated a highly significant difference $(p<.001)$. This observation is in accordance with Wagner's (1999) results for English. Second, past tense seems to be the most problematic category for both age groups, although the older children did better than the younger ones. Furthermore, the interpretation of future tense in the test sentences seems to cause some difficulties particularly to the younger group, whereas present tense seems to be have been acquired by both groups.

However, in order to evaluate how the subjects did with respect to the three different tenses, we need to analyze the data further. Figure 2 presents the response patterns of all children (i.e. both age groups) on the three tenses, past, present and future. Perfective and imprefective past forms are analysed together in Figure 2. 


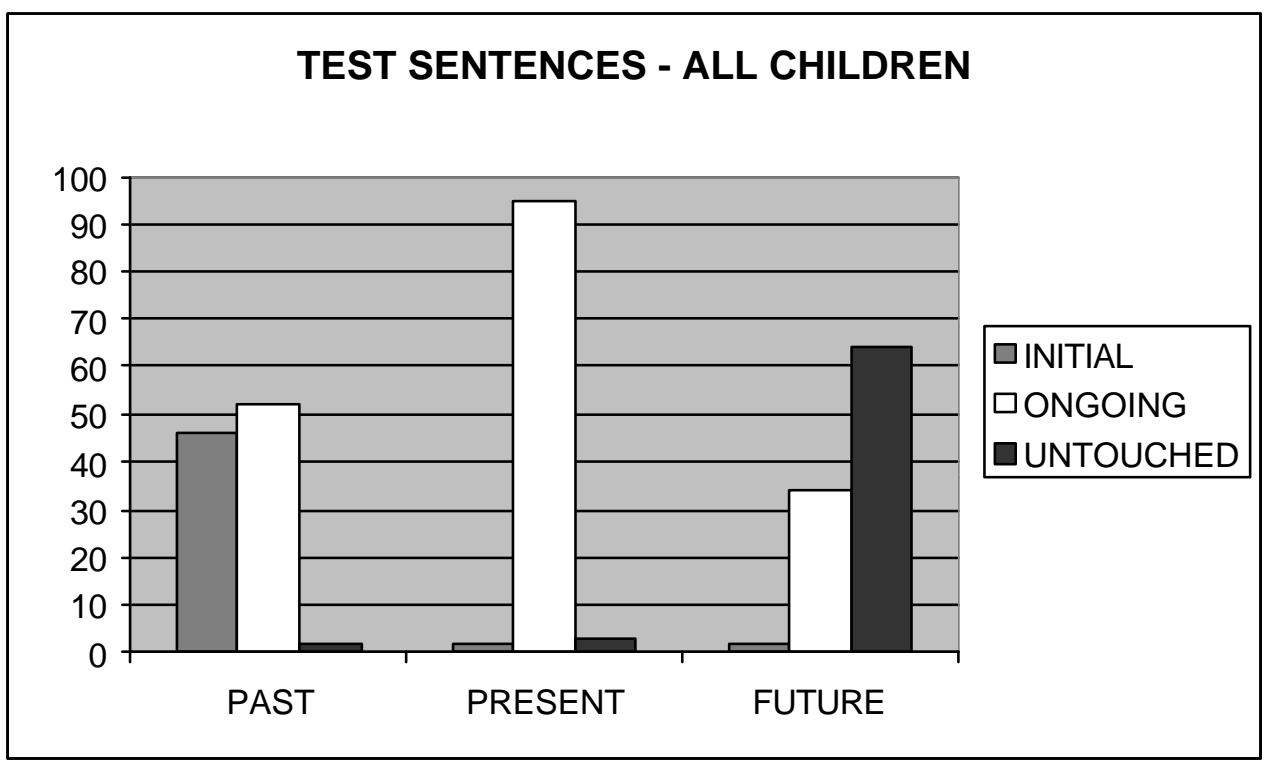

Figure 2. Response patterns on test sentences for all children

We can see that the ongoing location is the most common answer used by children when asked a past tense question. The ongoing location is selected $52 \%$ of the time, the initial location -which is the correct one- in $46 \%$ of the cases (which is not significantly above chance), while the untouched one only in $2 \%$ of the cases. We also observe that performance on present tense questions was almost always correct (95\%). The initial location was selected only $2 \%$ of the time and the untouched one only $3 \%$ of the time. In the case of future tense questions, although the untouched location -which is the correct one- was selected in $64 \%$ of the cases (which is significantly above chance), the ongoing location was also selected at a proportion of $34 \%$, while the initial one was selected only infrequently ( $2 \%$ of the time).

We will now examine if there is any difference regarding the understanding of the three time notions -past, present, future- in the two different age groups. We divided the 18 subjects in two groups. The younger group consists of 9 children aged 2;7 to 3;1 (mean age 2;8) and the older group consists of 9 children aged $3 ; 2$ to $4 ; 0$ (mean age $3 ; 6$ ). The response patterns for the younger group are illustrated in Figure 3, while the response patterns for the older group are presented in Figure 4. 


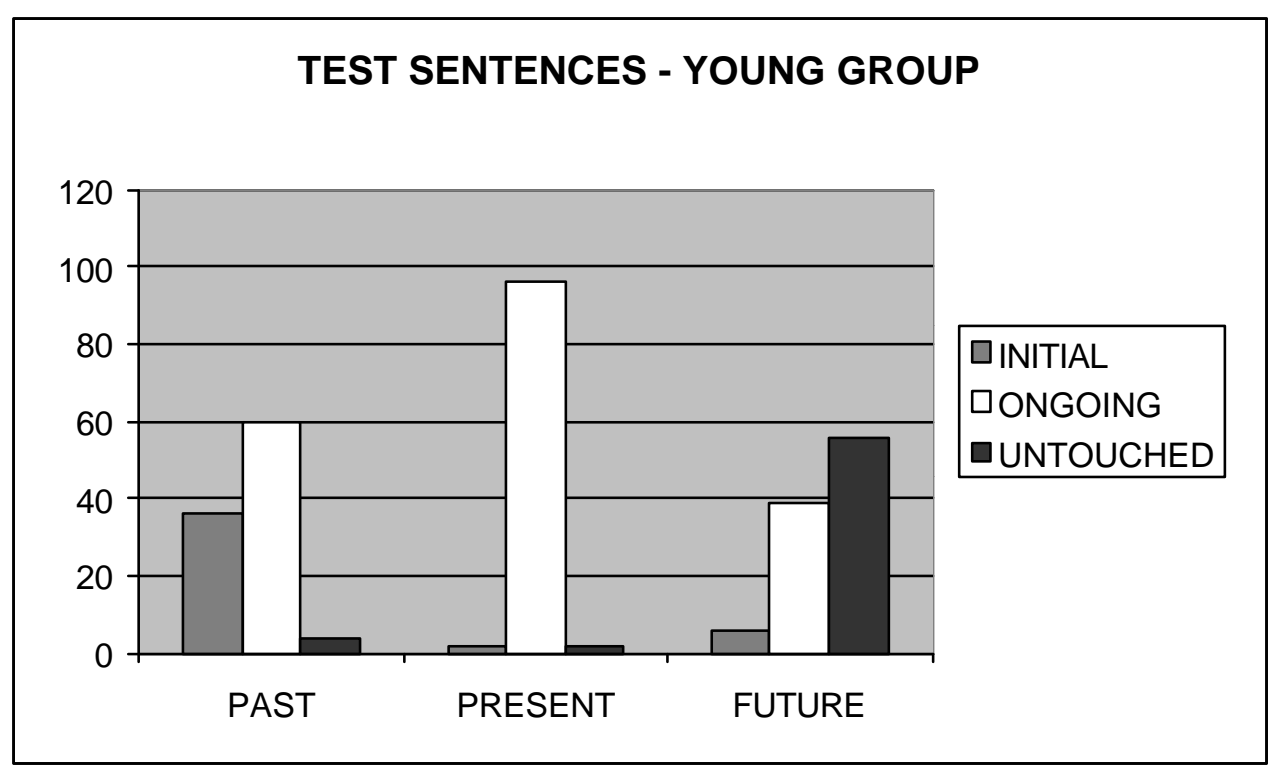

Figure 3. Interpretation of the three tenses for the younger group

Figure 3 shows that the past tense questions are the ones that mostly trouble the younger group. The initial location -which is the correct one- is selected in $36 \%$ of the cases (which is not significantly above chance) while the ongoing one in $60 \%$ of the cases; the untouched location is marginally selected (4\%). As far as present tense questions, the young group of subjects selects the correct location, the ongoing one, almost all the times. The percentage of correct answers is extremely high and reaches 96\%, while the initial location and the untouched location are selected only in $2 \%$ of the cases each. This is different from Wagner's (1999) results. In her experiment, the ongoing location was selected with present tense questions only $60 \%$ of the time. Finally, young children provide correct responses in the future questions in 55\% of the cases (which is significantly above chance), although present is selected approximately $39 \%$ of the time.

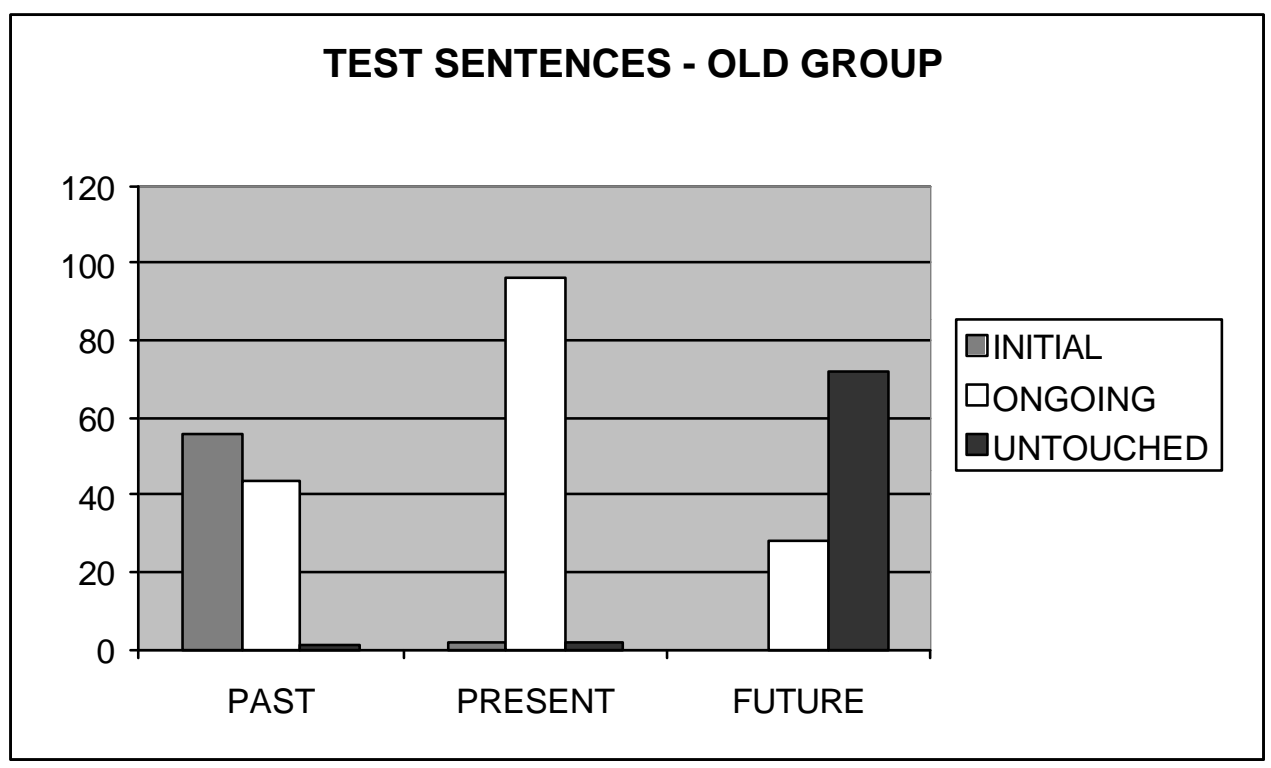

Figure 4. Interpretation of the three tenses for the older group

Figure 4 shows that the older children provide correct answers which are significantly above chance level performance for all types of questions. In the past tense questions, children use 
the initial location - which is the correct one- at a proportion significantly above chance (55.5\%), although present tense is also used (43.5\%). It is obvious that older children have a good grasp of the present tense as they select the ongoing location in $96 \%$ of the cases. Finally, in the future tense questions the subjects select the untouched location -which is the correct one- at a greater percentage than any other location (72\%), but they sometimes (28\% of the time) select the ongoing location instead of the untouched. It is worth mentioning that they never confuse past for future, that is they never select the initial location for future tense questions.

If we compare figures 3 and 4, it is evident that there was no difference in the interpretation of present tense between the two age groups. However, there is a difference in the interpretation of past and future tense. In order to find out whether this difference is significant, we performed a chi-square test. Our results indicated that the interpretation of past tense $(\mathrm{p}=$ $.004)$ as well as the interpretation of future tense $(\mathrm{p}=.011)$ improve significantly with age.

The results in Figures 2, 3 and 4 present the overall interpretation of past tense questions regardless of grammatical aspect. However, recall that our experiment contained two test conditions regarding past tense, one with perfective forms and one with imperfective forms. A difference was observed in the performance of the older children when the grammatical aspect of the past question changed. More specifically, as illustrated in Figure 5, the older group performed a bit better in the past tense when the form was imperfective rather than perfective. However, the results of an one proportion test showed that the difference in performance between perfective and imperfective forms was highly not significant $(p=.366)$.

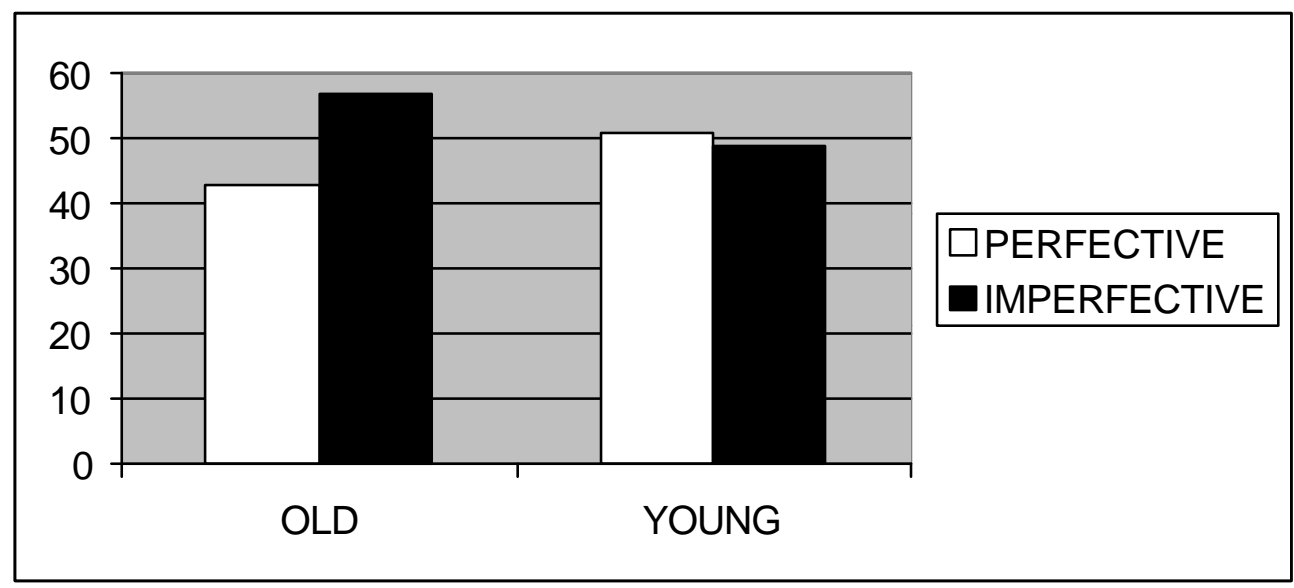

Figure 5. The effect of grammatical aspect on the comprehension of past tense questions

The role of lexical aspect in children's selection of location was also examined in the past tense queries. Figure 6 shows that the proportion of telic and atelic verbs in children's (both age groups) use of past tense (both perfective and imperfective) is about the same $(52.5 \%$ for telic and $47.5 \%$ for atelic). 


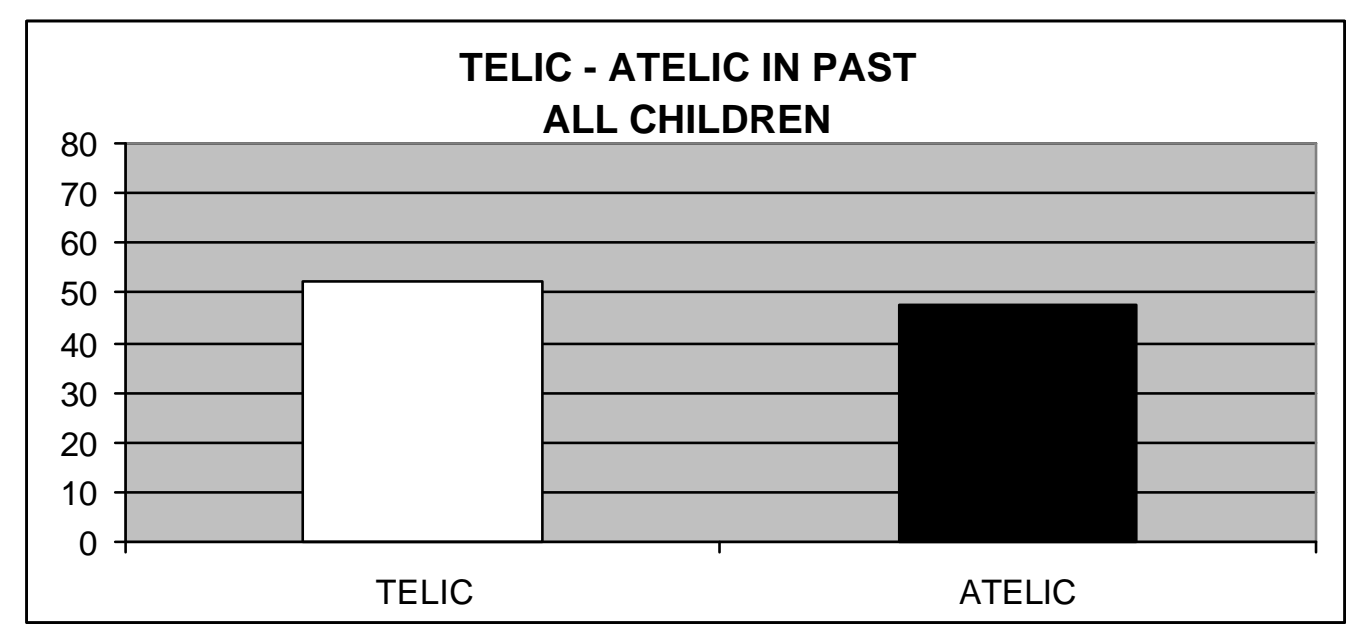

Figure 6. Percentage of telic and atelic verbs in past tense questions for both age groups

We also examined if there is a difference between the two age groups in their use of telic and atelic verbs in the production of past tense. Figure 7 illustrates that the proportion of the two types of predicates is exactly the same in the older group. Although the proportion of telic verbs in the younger group is a bit higher (56\%) that the proportion of the atelic predicates (44\%), a chi-square test indicated that the difference is highly not significant $(\mathrm{p}=.533)$.

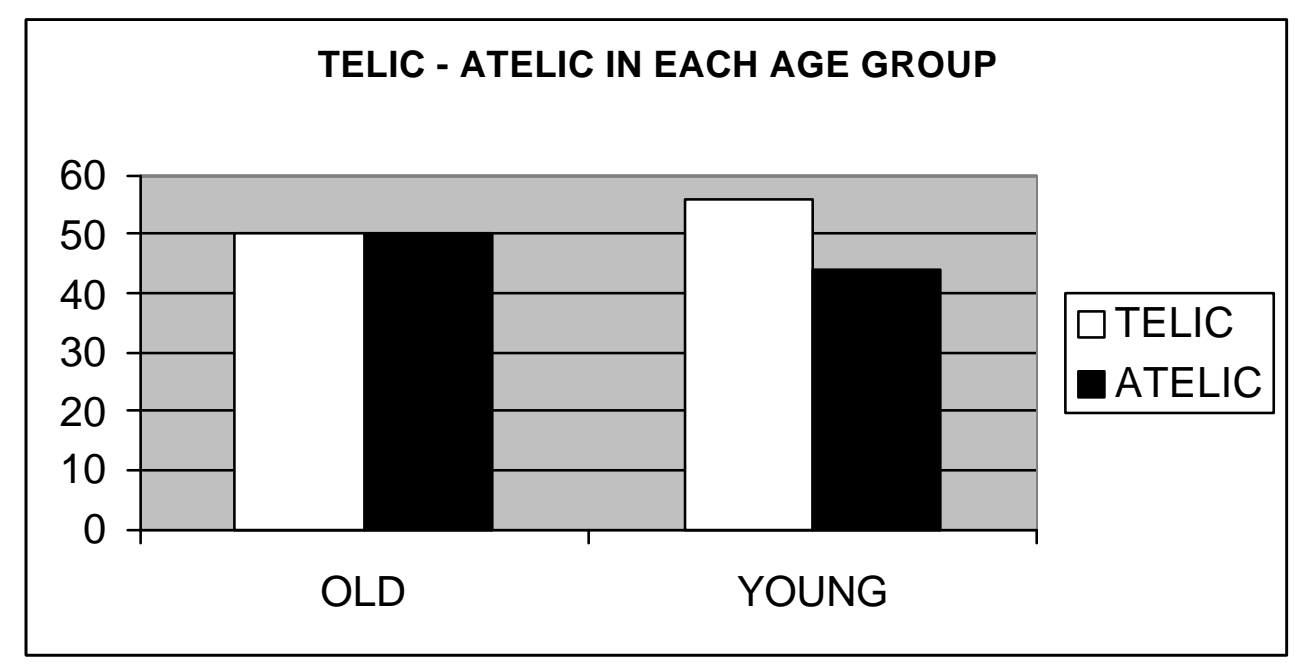

Figure 7. Percentage of telic and verbs in past tense questions for each age group

In order to see whether grammatical aspect plays a role in the choice of telic or atelic predicates, we calculated the use of telic and atelic predicates for each group according to grammatical aspect. Figure 8 illustrates that for the perfective past tense, the old group provides more correct answers with telic (61\%) than with atelic predicates (39\%), while there is no difference between the two in the younger group. A chi-sqare test indicated that the difference in the use of telic and atelic verbs is highly not significant $(p=.434)$. Figure 9 presents the use of telic and atelic verbs in the imperfective past tense queries for each group. Although the younger group provides more correct answers with telic predicates (63\%) while the older group with atelic verbs (59\%), a chi-sqaure test indicated that the difference is not significant $(\mathrm{p}=.125)$. 


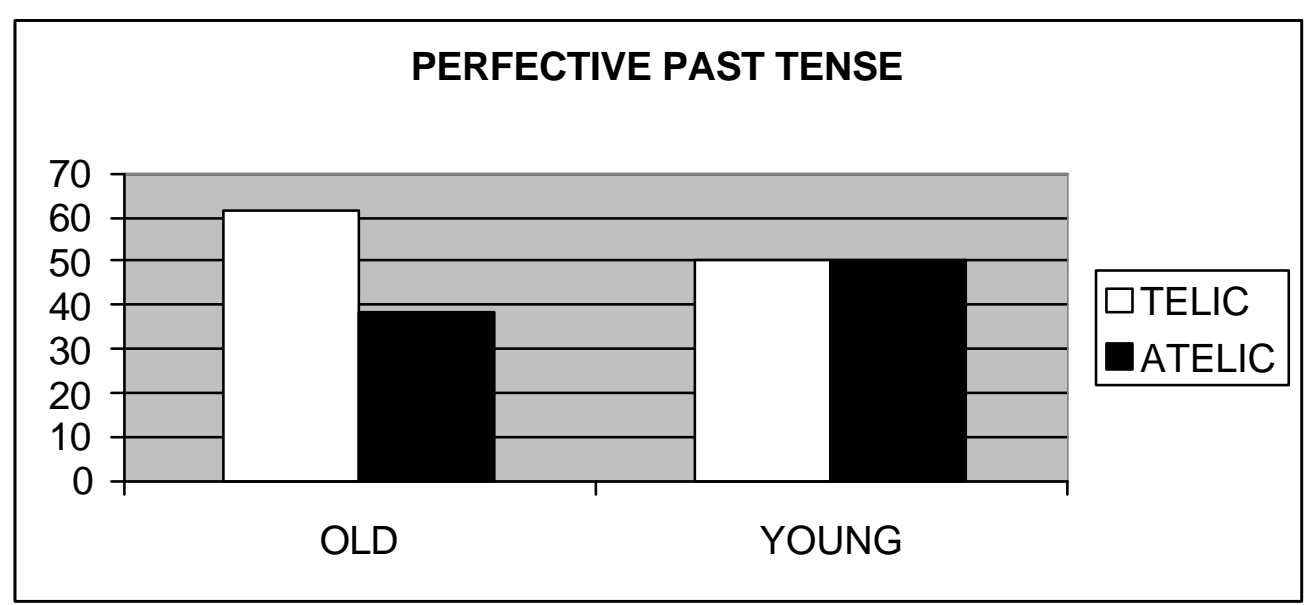

Figure 8. Percentage of telic and atelic verbs in the perfective past tense questions for each age group

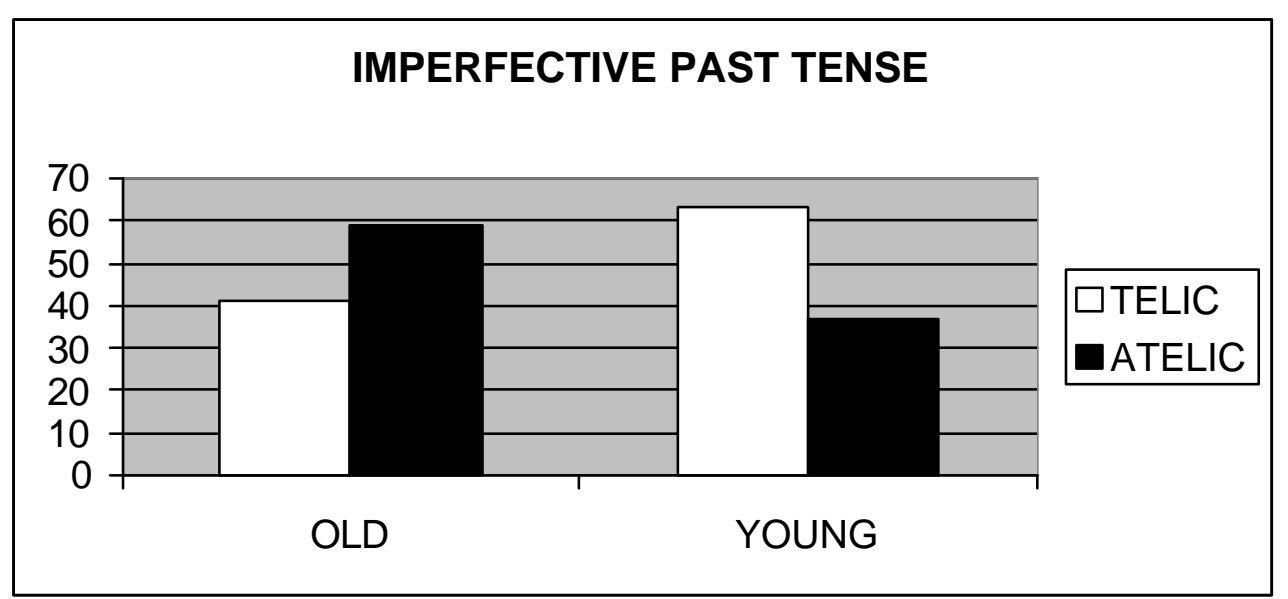

Figure 9. Percentage of telic and atelic verbs in imperfective past tense questions for each age group

\section{Conclusion}

The present study investigated the validity of the Aspect First Hypothesis in child Greek by testing Greek-speaking children's early comprehension of present, past and future tense morphology as well as the role of lexical aspect in the use of children's tense morphology. The main results of our study can be summarized as follows: a) Older Greek-speaking children ( $3 ; 2$ to $4 ; 0$ years old) understand tense better than younger ones $(2 ; 7-3 ; 1$ years old). Although present tense does not pose any problem, past and future tense seem to be problematic particularly for the younger group. b) Lexical aspect (i.e. telicity) of the predicate does not seem to play a significant role in the interpretation of the tense morphology in child Greek; there was no significant difference in the use of telic and atelic predicates with past forms for both age groups. c) Both age groups seem to be facilitated in their interpretation of tense morphology by the presence of linguistic cues such as time adverbials.

Based on our findings, we can conclude that Greek-speaking children aged 2;7 to 4;0 have not yet fully mapped the tense concepts to the correct tense morphology. However, the development of the tense system has already started at the age of 2;7 and after the age of 3;2 
all tenses but the past tense are almost fully mapped. Moreover, lexical aspect does not seem to affect significantly the acquisition of tense. According to the Aspect First Hypothesis, we would expect to find a strong correlation between the use of past tense forms and the telicity of the verb. However, the difference between telic and atelic verbs used with past tense forms in our experiment was not significant. We can conclude that tense acquisition does not seem to be significantly affected by the aspectual characteristics of the verb and in that respect the Aspect First Hypothesis does not seem to be confirmed by child Greek comprehension data.

\section{References}

Aksu-Koç, A. (1988): The Acquisition of Aspect and Modality. Cambridge: Cambridge University Press.

Antinucci, F. \& R. Miller (1976): How Children Talk about What Happened. Journal of Child Language 3, 167189.

Berman, R. (1983): Establishing Schema: Children's Construals of Verb-Tense Marking. Language Sciences 5, 61-78.

Bloom, L., Lifter, K. \& J. Hafitz (1980): Semantics of Verbs and the Development of Verb Inflection in Child Language. Language 56/2, 386-412.

Bronckart, J. P. \& H. Sinclair (1973): Time, Tense and Aspect. Cognition 2/1, 107-130.

Comrie, B. (1976): Aspect. Cambridge: Cambridge University Press.

Shirai, Y. \& R. Andersen (1995): The Acquisition of Tense-Aspect Morphology: A Prototype Account. Language 71/4, 743-762.

Stephany, U. (1981): Verbal Grammar in Early Modern Greek Child Language. In P. S. Dale \& D. Ingram (eds.): Child Language: An International Perspective, 45-57. Baltimore: University Park Press.

Weist, R. (1991): Spatial and Temporal Location in Child Language. First Language 11, 253-267.

Weist, R., Lyytinen, P., Wysocka, H. \& M. Atanassova (1997): The Interaction of Language and Thought in Children's Language Acquisition: A Crosslinguistic Study. Journal of Child Language 24, 81-121.

Weist R., Wysocka, H., Witkowska-Stadnik, K., Buczowska, E. \& E. Konieczna (1984): The Defective Tense Hypothesis: On the Emergence of Tense and Aspect in Child Polish. Journal of Child Language 11, 347374.

Wagner, L. (1999): Acquiring Tense in Form and Meaning. Proceedings of the 23rd Boston University Conference on Language Dedelopment, 708-719, Somerville, Mass.: Cascadilla Press. 